\title{
The Future of Sustainability: A Participant Motivation Model for Higher Education, Research, and Practice
}

\author{
Wendy Griswold ${ }^{1}$, Oral S. Saulters ${ }^{2 *}$, Amelia G. Young Sanders ${ }^{1}$ \\ ${ }^{1}$ Department of Leadership, School of Education, University of Memphis, Memphis, TN, USA \\ ${ }^{2}$ Center for Hazardous Substance Research, College of Engineering, Kansas State University, Manhattan, KS, USA \\ Email: *osaulter@ksu.edu
}

How to cite this paper: Griswold, W., Saulters, O. S., \& Sanders, A. G. Y. (2018). The Future of Sustainability: A Participant Motivation Model for Higher Education, Research, and Practice. Creative Education, 9, 406-425.

https://doi.org/10.4236/ce.2018.93029

Received: January 15, 2018

Accepted: March 11, 2018

Published: March 14, 2018

Copyright $\odot 2018$ by authors and Scientific Research Publishing Inc. This work is licensed under the Creative Commons Attribution International License (CC BY 4.0).

http://creativecommons.org/licenses/by/4.0/

\begin{abstract}
Environmental and sustainability education offer meaningful insights and instructive guidance for social-ecological systems. While some of the underlying concepts may be contested and even controversial, we submit that the overarching themes can contribute to healthy, balanced, and resilient individuals, organizations, and communities. Our study investigates student participation in a multidimensional Research Experience for Undergraduates (REU) program focused on building basic and applied research skill sets anchored in sustainable energy knowledge, and introduces use of a conceptual structure for evaluating outcomes: the Motivation, Core Competency, Research Skills and Sustainability (MCRS) Framework. We focus specifically on student motivation to pursue graduate education and sustainability careers. This is accomplished through an exploratory, multi-strand, case-oriented study, utilizing mixed methods to analyze qualitative and quantitative evaluation data. The literature foundations for the study include undergraduate research experiences and graduate education, learning contexts, and key sustainability education competencies. Findings suggest that the program impacted the desire of participants to attend graduate school and aided in their development of clarity around future sustainability-related career paths. Research concentrates on a group of undergraduates in a STEM-related sustainable energy program as part of an important approach which can be applicable to other programs in differing fields and contexts. Understanding learner motivations with respect to designated competencies and skills is a positive step in creating education systems supportive of equitable and sustainable societies. Expanded use of the MCRS Framework into a logic model for integrated problem solving and evaluating performance outcomes can provide direction for informed planning and decision making toward improved policies, programs, and projects now and into the future.
\end{abstract}




\section{Keywords}

Environmental Education, Sustainability, Motivation, Competencies, Research Experience for Undergraduates

\section{Introduction}

In this precarious Anthropocene Age, improved interdisciplinary models of teaching, learning, and research are needed for a more sustainable future (Sachs, 2015). From recent U.S. controversies like the Dakota Access Pipeline, which is pitting energy development interests against Native American stakeholders, and the governance/water quality tragedy in Flint, Michigan to global conundrums with myriad local and regional dimensions such as climate change, declared by former UN Secretary-General Ban Ki-moon as "the moral challenge of our generation" (The Guardian, 2007), the imperative need for sustainability competencies is becoming increasingly clear. Despite the growing demand for qualified STEM professionals, most undergraduate students beginning in these disciplines either change majors or do not finish (Van Soom \& Donche, 2014). This presents many problems for economic competitiveness, science literacy, and future educators (Kober, 2015). For example, transitioning to a sustainable energy economy is a critical grand challenge of global concern (Erickson et al., 2017; National Science Board, 2009); meeting this demand successfully will take a concerted strategic effort (Incropera, 2016). Advancing education, workforce development, public awareness, and action are among important recommendations for underpinning this historical transformation. Accordingly, the National Science Foundation-sponsored Earth, Wind \& Fire Research Experience for Undergraduates (EW\&F REU) Program is designed to expose students to interdisciplinary research inspiring graduate studies and sustainability careers toward addressing this crucial need (Erickson et al., 2010).

What causes students to take action toward pursuing graduate studies and sustainability careers? This simple but salient question anchors this analysis exploring STEM education through the prism of an energy research and sustainability training program. The aim is to explain the impact of the EW\&F REU on student motivation to pursue graduate education, core competencies gained, students' skill and ability to conduct research, and the impact on students' intentions to participate in environmental sustainability. These are discussed in the Motivation, Competencies, Research skills, and Sustainability impact (MCRS) framework highlighting the progression of student experience in the EW\&F REU with implications for the future of sustainability education, research, and practice.

\section{Background}

Three areas support this exploration: 1) undergraduate research experiences and 
graduate education; 2) learning contexts; and 3) key competencies in education for sustainability. With respect to student experiences within research and graduate education, this literature review discusses why students engage in scholarly research, how this affects their pursuit of graduate education, barriers to graduate education, and instructor's role. Learning contexts explored include the lasting effects of undergraduate research programs and situated learning in communities. Operational definitions of sustainability and education for sustainability are presented, as well as an overview of key sustainability competencies.

\subsection{Undergraduate Research Experiences and Graduate Education}

This section discusses key theories and issues in undergraduate research and pursuing graduate education, such as motivation, satisfaction, pursuit of graduate education, barriers to graduate education, and instructor immediacy and mentoring.

\subsection{Motivation}

A growing importance is being placed on student participation and motivation today in higher education. Student motivation is the value a student places on learning a task or concept and their personal interest in the concept, task, instructor, or school (Cayanus \& Martin, 2008). There is a great sense of importance concerning motivation in science research, as motivation is a driving force of information-seeking students. McClelland (1967) created the Theory of Achievement Motivation which identifies three needs a student has: achievement, affiliation, and power. One of these traits can be more dominant based on individual personality. This theory states that people create their own intrinsic rewards such as curiosity for a topic or a strong sense of accomplishment (McClelland, 1967). By introducing ways to increase student motivation to learn, the strength of the intention and behavior will increase. One goal of most sustainability courses and programs is to inspire a change of attitude or behavior, both of which begin with the motivation of the individual (Arbuthnott, 2009).

\subsection{Student Satisfaction}

Universities can best recruit and retain students through identifying and meeting their needs and expectations (Kamil Anil \& Eti Icli, 2013). Satisfaction levels are determined by the differences between the actual service performance as perceived by the student and their expectations. A variety of factors appear to influence student satisfaction in higher education, and it is possible to increase quality and satisfaction by meeting students' desires and needs (Kamil Anil \& Eti Icli, 2013).

Motivation and student satisfaction are qualities exercised by students who plan on pursuing graduate studies, but these qualities alone are not enough to overcome existing barriers to graduate education today. 


\subsection{The Pursuit of Graduate Education}

Most incoming freshmen indicate they plan to pursue a post-baccalaureate degree (Pascarella \& Terenzini, 1991). This decision is heavily influenced by a student's undergraduate research experience (Astin, 1993). Research shows that involvement in interdisciplinary courses, workshops, and undergraduate research opportunities as well as interacting with faculty are all factors that can influence educational aspirations (Astin, 1993; Pascarella \& Terenzini, 1991; Tinto, 1993). Faculty-student interaction, in particular, appears to play a vital role in academic achievement, student retention, institutional satisfaction, and a student's decision to pursue graduate education (Hearn, 1987).

As noted above, one of the strongest indicators of pursuing graduate study is a student's research experience as an undergraduate. Students who report having a positive undergraduate research experience often report a higher interest in careers in the science, technology, engineering, and mathematics (STEM) workforce (Zydney et al., 2002). Several studies have supported the hypothesis that undergraduate research helps promote career pathways for members of underrepresented groups by increasing the retention rate of minority undergraduates (Gregerman et al., 1998) and increasing the graduate rate (Hathaway et al., 2002). The benefits associated with a graduate degree can be lucrative; nevertheless many interested students face barriers.

\subsection{Pushing Through Barriers}

A number of institutional and personal barriers exist in the pursuit of graduate education, such as economic challenges, sociocultural incongruence, and student anxiety. Graduate education today is more expensive, and institutions are less likely to offer financial support in terms of tuition and waivers (Bowen \& $\mathrm{Ru}$ denstine, 1992). Because of the perceived academic culture of some fields, mainly the sciences, graduate school becomes less attractive to women and minority students who can feel isolated (Seymour, 1995a, 1995b). There have been many efforts focused on preparing and attracting undergraduates to pursue further education. Recruiting and retaining underrepresented students is also a top concern. Another possible barrier involves student-instructor miscommunication related to student anxiety. Fears and anxiety can be learned from direct occurrences of threats or indirectly as a result of observing others who experience threatening incidents (Bledsoe \& Baskin, 2014). For most, the classroom represents a platform for academic success or a place to build relationships with other people and where an instructor can help guide and comfort, but for some an instructor may be seen as a distant, cruel, and judgmental figure (Cox, 2009).

Research shows that a student's undergraduate experiences play a significant role in their pursuit of graduate study (Astin, 1993; Hearn, 1987; Pascarella \& Terenzini, 1991). For example, students who regularly attend diversity workshops, take interdisciplinary courses, participate on research projects, and interact with faculty are all factors that appear to influence one's educational aspirations 
(Astin, 1993; Pascarella \& Terenzini, 1991; Tinto, 1993). Faculty-student interaction, in particular, is a factor that appears to play a pivotal role not only in academic achievement, student retention, and institutional satisfaction, but it strongly influences students' decisions to pursue further education (Astin, 1993; Pascarella \& Terenzini, 1991).

\subsection{Instructor Immediacy and Mentoring}

Instructor immediacy is the term used to describe communication behaviors that reduce the perceived distance between teacher and students and enhance instructors' communicative power and interpersonal relationships with students. This study explores various dimensions of the student experience including relationships between faculties and peers; therefore, it is necessary to look at the importance of faculty and peer immediacy. Immediacy comprises nonverbal cues and draws attention to the verbal message (Khanam et al., 2012). One of the most consistent and important findings in the literature is that instructor immediacy has a positive effect on perceived cognitive learning, affective learning, and willingness of students to engage in the theories, lessons, and practices taught in their courses (Khanam et al., 2012).

In this knowledge-based world-wide economy, what students are capable of learning in the future is just as important as how much they know when they graduate. It is essential that they have the ability to adapt quickly to new situations and solve difficult problems, and research skills greatly enhance that capacity. Because of this, research has penetrated the undergraduate experience. With this shift in priorities, mentoring skills and opportunities have found a great deal of appreciation among students whose needs have changed. The more decisions they are asked to make, the more guidance they want (Gonzalez, 2001). Research experiences for undergraduates can be a deciding factor for overcoming certain barriers to higher education and being prepared for graduate study, and these research experiences are best exemplified through research experience programs for undergraduates.

\subsection{Learning Contexts}

Two learning contexts are discussed. Research experiences for undergraduates are a specific context geared toward encouraging students to pursue STEM careers through advanced degrees. Situated learning in communities is a more general context, but highly relevant to the development of sustainable societies.

Research experiences for undergraduates. Research experiences for undergraduates (REU) have been identified as deciding factors for the pursuit of graduate study as a result of increased academic success. REUs or Undergraduate Research Opportunities (UROP) were originally developed in 1988 to increase student retention and improve the academic performance of underrepresented students of color at a large Midwestern research university (Hathaway et al., 2002). UROP was developed to get undergraduates, involved with faculty, 
research, and acquire an interest in research-related or academic careers. These programs are successful in accomplishing their goals of retention and academic success (Hathaway et al., 2002).

\subsection{Situated Learning in Communities}

Leve and Wegner (1991) explored situated learning in communities with an emphasis on engagement and relationship as the site of learning. Situated learning involves "the whole person rather than 'receiving' a body of factual knowledge about the world; an activity in and with the world, and on the view that agent, activity, and the world mutually constitute each other" (Leve \& Wegner, 1991: p. 33). The capacity of situated learning is of particular relevance to education for sustainability. According to their theory of legitimate peripheral participation, participation (or engagement) in relation to 'old-timers' is the process by which newcomers form their identities in respective communities of practice (Leve \& Wegner, 1991). Situated learning may be an appropriate tool for the creation of sustainable societies, where "old" ways of acting and thinking may be problematic. While new members of a community need to learn from the previous generation, they also need to transform the perspectives and practices in order to develop a distinct identity and move toward the future (Leve \& Wegner, 1991). Learning communities can serve as sites for introducing newcomers into more encompassing communities of practice.

\subsection{Key Competencies in Education for Sustainability}

As sustainability and education for sustainability are highly contested concepts, the definitions guiding this analysis are provided. According to John Ehrenfeld, industrial ecologist and author of Sustainability by Design, sustainability is "the possibility that human and other life will flourish on the planet forever" (2008), which we adopt as our vision of sustainability. We believe that in order to move toward sustainability, humanity requires "an education that prepares people to be far-seeing enough, flexible enough, and wise enough to contribute to the regenerative capacity of the physical and social systems upon which they depend" (Cloud Institute for Sustainability, 2009). These definitions provide guidance in determining the competencies needed to develop sustainable societies.

Through a broad survey of relevant theory and practice, the American Association for the Advancement of Science (2010) and Wiek et al. (2011) have identified key competencies in sustainability and crafted a framework for informing academic research and program development. In terms of sustainability, competencies are defined as "complexes of knowledge, skills, and attitudes that enable successful task performance and problem solving with respect to real-world sustainability problems, challenges, and opportunities" (Wiek et al., 2011: p. 204). Specifically, these five interdependent domains include: 1) systems-thinking (variables, scales, and feedback); 2) anticipatory (time, uncertainty, intergenerational); 3) normative (principles, justice, ethics); 4) strategic (transitions, adaptation, 
social learning); and 5) interpersonal (collaboration, teams, leadership) competencies. Each of these functional realms comprises versatile and robust capacities. Systems-thinking competence involves the ability to holistically analyze complex systems across different scales, sectors, and domains. Anticipatory competence is the ability to effectively imagine and create visualizations or pictures of future sustainability-related scenarios. Normative competence is the capability to comprehensively map, reconcile, and negotiate underlying values, beliefs, ethics, principles, and biases toward what should be in a given context. Strategic competence is the ability to design and implement transitions, interventions, and solutions toward sustainability while considering political dimensions and unintended consequences. Interpersonal competence is the ability to listen, communicate, and facilitate collaboration and participatory approaches across diverse interests, perspectives, and cultures. Although the sustainability literature includes many litanies of concepts, terminology, and nomenclature, the importance of overarching and unifying sustainability frameworks cannot be overemphasized (National Research Council, 2011). The integrated research and problem-solving model by Wiek et al. (2011) provides key steps including: problem identification, visioning, scenario planning (given key points of intervention), and strategic implementation.

\section{Participants and Program Composition}

Since 2009, Kansas State University has offered a 10-week summer program, Earth, Wind \& Fire Research Experience for Undergraduates, to undergraduate science and engineering students (Erickson et al., 2010). The program, funded by the National Science Foundation's REU Program, involved 67 students in sustainable energy research from 2009-2015. Program participants are science and engineering undergraduate students drawn from all over the U.S. Typical participants are in their junior or senior year. Most students have GPAs of 3.5 or higher, participate in volunteer and service activities and have previously won academic awards. With respect to the research reported here, based on continuous improvements to program structure, content, and processes resulting from various sources of feedback, data are focused on ten participants in the 2015 summer program.

The EW\&F REU has nine components giving participants opportunities to enhance their understanding of sustainability, participate in research projects, and develop professionally.

1) Mentored research-work with faculty and graduate student mentors. Several participants publish articles on their research (Erickson et al., 2017; Goldin, et al., 2014; Robinson et al., 2014).

2) Sustainability seminar-one credit seminar providing exposure to a range of sustainability issues addressing energy as well as other relevant topics.

3) Research meetings/presentations and symposium-weekly meetings to share individual research results. Culminates in a research poster symposium. 
4) Sustainable energy field trips-wind farm and biofuel production facility.

5) Professional development seminars-sponsored by the university's graduate school.

6) Brownbag lunches-informal discussion on participant chosen sustainability topics.

7) Group projects-Past projects include creating exhibits on sustainable energy, developing a position paper on greenhouse gas emissions reduction strategies, and teaching sustainability science at youth workshops.

8) Dialog on Sustainability-provides the opportunity to interact with practicing professionals, local community residents, organizations, and other stakeholders involved in sustainability efforts.

9) Reflective journaling-guided prompts related to program elements and general issues.

The setting provides two additional key elements in the robust learning experience: connection to natural surroundings and diversity of thought. K-State is in the Flint Hills and is home to the Konza Prairie Long-Term Ecological Research Site, the largest North American tallgrass prairie and part of the state-of-the-art National Ecological Observatory Network (NEON) continental scale platform. Participants can connect with outdoor recreational environments and explore sustainability in a different geographic setting. K-State is also home to the Center for Hazardous Substance Research, which provides institutional and mentoring support, with over 25 years of EPA-sponsored technology development, transfer, and outreach to diverse communities. Along with several additional REUs, the EW\&F REU provides opportunity to interact with peers in biology, math, physics, chemistry, and other engineering communities. For most participants, this is their first significant research experience and their first immersion in a multidisciplinary learning community.

\section{Methodology}

This research discusses data collected and analyzed with respect to the impact of the program on participants' intentions to pursue graduate education and be involved in environmental sustainability in their future careers. Qualitative and quantitative data were used in the analysis. Mixed methods were selected as the research explored complex issues, necessitating the use of multiple research questions to provide a more complete picture of the participants' experience (Mertens \& McLaughlin, 2004). As this was an exploratory, multi-strand, case-oriented study, the use of mixed methods allowed for triangulation of data and the ability to substantiate each strand's findings more fully (Teddlie \& Tashakkori, 2009). A parallel mixed data analysis design (Teddlie \& Tashakkori, 2009) was used to analyze data. Data collection methods were designed to answer related aspects of the research questions. The qualitative and quantitative data were collected in a parallel and separate manner. Data were analyzed separately using methods appropriate to the respective strands. Following the analysis 
of the separate strands, a meta-inference process was used to identify instances of convergence and divergence in the data, according to procedures outlined by Teddlie and Tashakkori (2009).

Ten students participated in the program during summer 2015 and signed informed consent documents. Data sources include student journals, a focus group, a pre-post survey, and a follow-up survey conducted six months after the program ended. REU participants were required to submit weekly journal entries during weeks 1-9 of the program. Guided prompts were provided to facilitate participant journaling on their specific activities in the program. In addition, participants wrote on topics of their choice. Journal entries were submitted electronically to the researchers. They also participated in a focus group at the end of the program. The focus group was conducted by one of the researchers, and the recording of the session was transcribed by another. Qualitative data were managed using NVivo 10 to create a database. The data were coded using grounded theory method to discover the patterns, themes and categories of the participants' experiences (Charmaz, 2006). Cohen's Kappa (Hinkle et al., 2003) was calculated on several codes used in the analysis of the data to assess inter-rater reliability. The researchers conclude that the inter-rater reliability is satisfactory, as the Kappa of all coding examined is greater than the commonly applied criteria of .70, with $64 \%$ - $94 \%$ of coded items having a Kappa of .99 or higher.

The surveys focused on participants' perception of research careers, attitudes toward research and sustainability, career goals, and confidence levels related to research abilities and technical/scientific knowledge. All quantitative data were managed using IBM's Statistical Package for the Social Sciences (SPSS) software and analyzed for frequencies.

\section{Findings}

Data analysis has resulted in the development of an initial conceptual framework highlighting the progression of participants' experience beginning with motivational factors leading to the development of core competencies and enhanced research skills, which results in their ability to have impact on sustainability. Figure 1 is a logic model of this emerging framework.

Motivation has been identified as an essential factor in understanding student learning, performance, and behavior. In particular, Self-Determination Theory (Deci \& Ryan, 1985) posits motivation as a complex and multidimensional construct, which has been applied to education in various levels and settings. The five key competencies in sustainability as synthesized by Wiek et al. (2011) offer an instructive approach to sustainability research and problem-solving as expressed by the REU. Both motivation and core competencies are iteratively linked with the EW\&F REU program elements which foster research skills and ultimately sustainability impact in various ways including graduate studies and professional application. This is effectively captured by the Motivation, Core Competency, Research Skill, and Sustainability Impact (MCRS) conceptual 


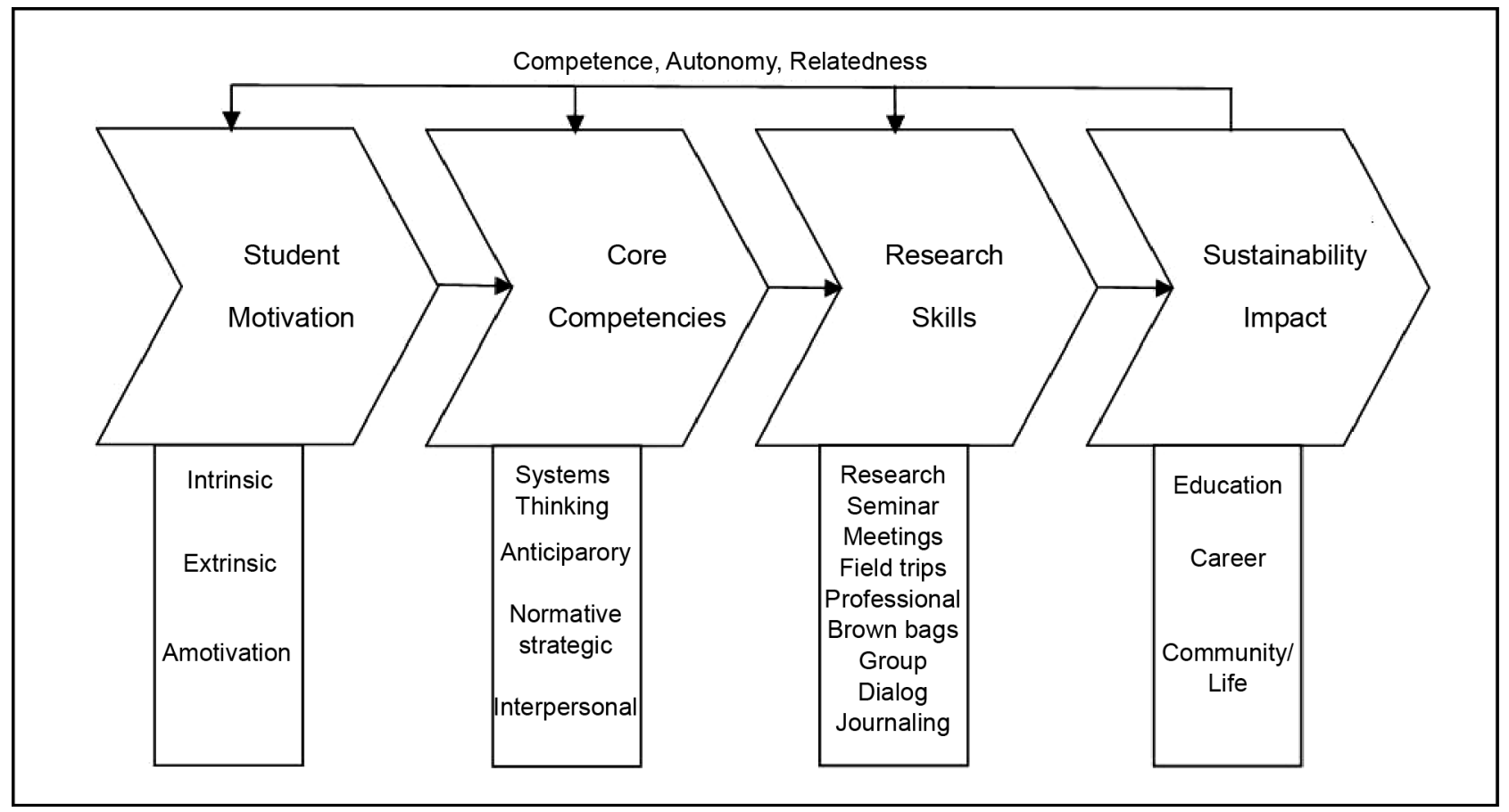

Figure 1. Logic model of participant experience.

framework. Each element of the framework is discussed below with examples drawn from the data.

\subsection{Motivation}

In this context, motivation operationally indicates that students be moved to do something. We are interested in both the level (amount) and the orientation (type) of motivation as used by Ryan and Deci (2000). Motivation is more than a unitary phenomenon and is characterized as a dynamic continuum between intrinsic (internal self-determination), extrinsic (wide ranging and external-instrumentally driven), and amotivation (lacking intention) states. Moreover, learning environments which facilitate competency, autonomy, and relatedness contribute to internalization and integration processes toward student self-determination across various college subgroups (Hegarty, 2010; Köseoğlu, 2013; Ryan \& Deci, 2000; Van Soom \& Donche, 2014). The literature reveals that students respond with greater motivation when they believe their tasks or instructors are both clear and relevant. This applies to all fields including the sciences.

Investigating what drives student action within and beyond EW\&F REU is the first step in assessment. Specifically, estimating where on the motivational continuum one is (characterizing general distinction between internal and external impetus), helps inform how participants might pursue sustainability choices such as those involving further STEM education, career, and lifestyle. Based on our analysis of qualitative data, we did find evidence of student motivation correlated with each aspect (i.e., intrinsic, extrinsic, and amotivation) and associated processes. In particular, key themes were identified from grounded theoretical 
approaches. Emergent categories and examples are summarized in Table 1.

Findings indicate that the quality of experience and performance varied according to behavior determined for intrinsic logics (internally-driven) as recognized in personal background, beliefs, values, and achieving research results. Examples include inherent enjoyment based on views and values of nature, making progress in the program, and enjoyment from learning new things. These are broadly contrasted with extrinsic reasons (externally-driven) such as interactions with mentors, graduate students, and social expansion. For REU students, working closely with graduate students and mentors via hands-on training appeared to build confidence and facilitate openness to new ideas and experiences such as joining an environmental conservation group. These results are consistent with educational literature outcomes regarding motivation in pursuit of graduate education. Moreover, these data suggest mechanisms serving as feedback pathways which contribute to meeting psychological needs and affective elements (i.e., competence, autonomy, and relatedness) essential for student satisfaction and mitigating anxiety as previously discussed. Amotivational factors including low-perceived competence and emotional frustrations appeared less frequently than more strongly motivational reasons for participants and suggest temporal influences with respect to becoming more familiar with discipline-specific nomenclature, methods, and program processes.

Quantitative data collected by pre and post surveys provide insight into the students' motivations for participating in the REU program. Their most obvious motivation is to explore their interests in science and engineering careers and to learn what graduate school might be like (see Figure 2 and Figure 3 ). Sixty percent of participants reported they were interested or very interested in attending graduate school and pursuing a career in research when they entered the program. The program was seen as helpful to achieving their professional goals, as $100 \%$

Table 1. Themes and examples of student motivations.

\begin{tabular}{|c|c|c|c|}
\hline $\begin{array}{l}\text { Motivation } \\
\text { Dimension }^{1}\end{array}$ & Associated Processes ${ }^{1}$ & Participant Themes & Examples \\
\hline Amotivation & $\begin{array}{l}\text { Perceived non-contingency; } \\
\text { Low perceived competence; } \\
\text { Non relevance; Non intentionality }\end{array}$ & $\begin{array}{l}\text { Emotions; Frustrations; } \\
\text { Persistence; Structure }\end{array}$ & $\begin{array}{l}\text { "I'm not a microbiologist"; "I felt } \\
\text { unprepared"; "I am like the most } \\
\text { impatient person ever" }\end{array}$ \\
\hline
\end{tabular}

Note: ${ }^{1}$ Ryan, and Deci, 2000. 


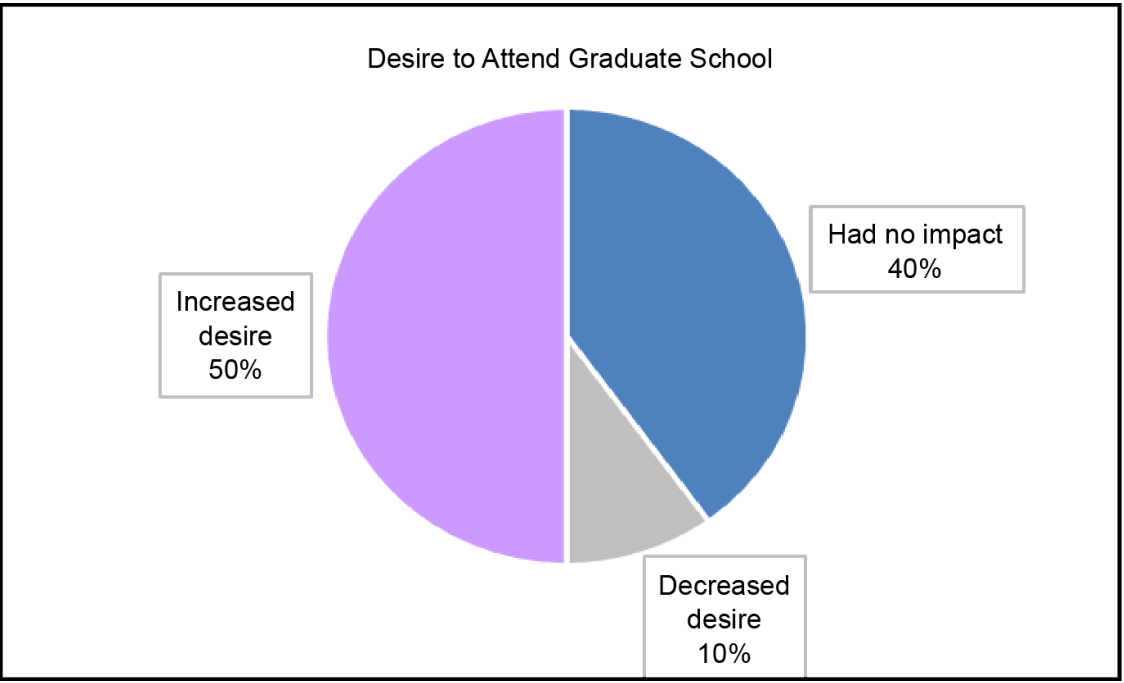

Figure 2. Impact of program on participants' desire to attend graduate school.

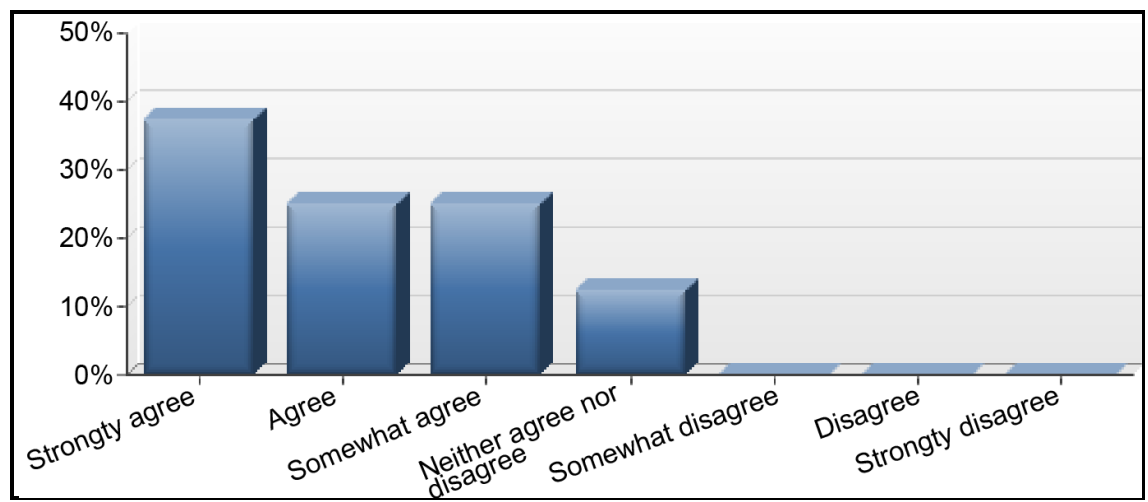

Figure 3. Participants level of agreement with the statement "I plan to pursue a career involving environmental sustainability."

agreed or strongly agreed that their participation in the REU program would be beneficial to their career.

Additional motivation for participation may include highly valuing environmental sustainability and the contributions research makes to society. Ninety percent reported that environmental sustainability is very to extremely important to them. One hundred percent agreed or strongly agreed that conducting research makes an important contribution to society and $80 \%$ agreed or strongly agreed that research is important to addressing current environmental issues.

The results from questions asking about participants' interest in attending graduate school and pursuing research careers, and specific plans for pursuing graduate degrees indicate that their experience in the REU program has no impact on graduate school plans (at least in the short term). However, a question asked on the post survey shows that for half of participants, their experiences in the program increased their desire to attend graduate school. This may indicate an increase in motivation to attend graduate school and a greater likelihood of carrying through on their intentions. 


\subsection{Core Competencies}

In accordance with Wiek et al. (2011), we use the general definition of sustainability competencies to denote nested aggregates of knowledge, skills, and attitudes that facilitate successful task performance and problem solving, as manifested in systems, anticipatory, normative, strategic, and interpersonal capabilities. The nascent academic field of sustainability has gained considerable traction in scholarship and practice, and involves many interdisciplinary elements. Key competencies, learning outcomes and conceptual framework for research and problem solving have been developed (Wiek et al., 2011). Qualitative examples of core competencies (e.g., Systems Thinking, Anticipatory, Normative, Strategic, Interpersonal) and linkages with the EW\&F REU program were discerned through participants' descriptions of programmatic activities including assigned projects, field trips, goals, lab research, program expectations, seminars, and weekly journals. Sustainability science uses knowledge, tools, and technologies from many STEM fields to pragmatically solve complex problems. For example, energy puzzles such as those investigated in the REU related to the electrification of transportation are multivalent requiring local through global-scale considerations across ecological, socioeconomic, and techno-political systems. This provided both challenges and opportunities. For instance, some students were tasked with defining metrics and others with engaging stakeholders by communicating technical data with general audiences. Many of these activities go beyond the scope of a traditional undergraduate course and constraints of a conventional brick-and-mortar classroom setting. The EW\&F REU experience helped students build important research skills as embodied in core competencies which culminated in enhanced capacity and motivation for mindfully sustainable actions. Connections between core competencies, program components, and problem-solving framework are illustrated in Figure 4 and offer a practical overview and instructive guide.

Quantitative data are related to three areas of core competencies: knowledge about sustainability, valuing collaboration, and understanding the life of a researcher. With respect to knowledge about sustainability, at the onset of the program, 30\% reported that their knowledge of environmental sustainability was high to very high. While the difference in means was not statistically significant for this question, there was a shift in pre-post responses. On the post-survey, this figure rose to $70 \%$ indicating at least an increased perception in their level of knowledge about environmental sustainability. Two questions asked only on the post survey related to learning about sustainability. Eighty percent of participants agreed or strongly agreed that as a result of the REU, they viewed sustainability as an applied, multidisciplinary field. Forty percent agreed or strongly agreed that the team project enhanced their understanding of sustainability.

Multidisciplinary collaboration and building relationships are important components of the program, as well as efforts to advance sustainability. There was a high level of agreement about the value of these components among 


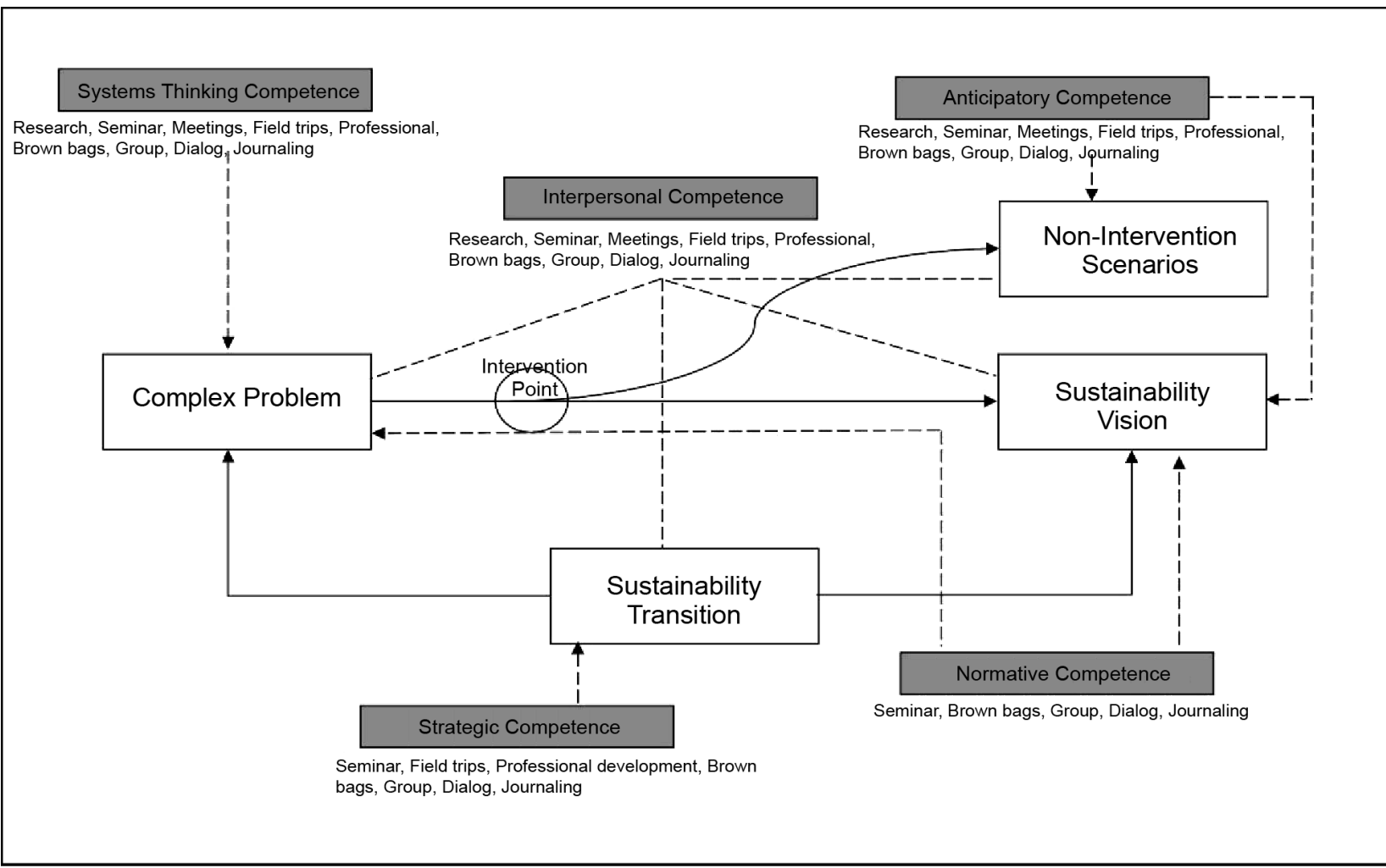

Figure 4. Integrated model of sustainability competencies, REU program components, and problem solving framework (Adapted from Wiek et al., 2011).

participants. Eighty percent agreed or strongly agreed that the opportunity to work with people from disciplines other than their own was valuable. With respect to relationships with other program participants, $80 \%$ agreed or strongly agreed they were an important component of the REU experience.

The REU experience provides participants with opportunities to explore life as a researcher. For some, this is their first opportunity to gain firsthand knowledge and experience as members of the research community. Participants' knowledge about the daily life of researchers and graduate students was very low at the outset of the program, with $20 \%$ agreeing or strongly agreeing they had a good idea of what a graduate student's life was like and 30\% agreeing or strongly agreeing they had a good idea of what a researcher's life was like. At the end of the program, rates of agreement for both questions was $80 \%$, reflecting a statistically significant change (graduate students-pre: $\mathrm{M}=4.5, \mathrm{SD}=1.650$, post: $\mathrm{M}=5.9$, $\mathrm{SD}=.876 ; \mathrm{t}(9)=-3.280, \mathrm{p}=.01$, researchers-pre: $\mathrm{M}=4.8, \mathrm{SD}=1.549$, post: $\mathrm{M}=6.1, \mathrm{SD}=.738 ; \mathrm{t}(9)=-2.751, \mathrm{p}=.02)$.

\subsection{Research Skills}

A cornerstone of the EW\&F REU is transformative research skills. According to NSF (2007), this involves ideas, discoveries, or tools that radically change our understanding of an important existing scientific or engineering concept or educational practice or leads to the creation of a new paradigm or field of 
science, engineering, or education; such research challenges current understanding or provides pathways to new frontiers. Particularly, this is encapsulated in program initiatives that range from hands-on laboratory training and technical communications to professional development seminars and fields trips to personal reflection/contemplation journaling to community outreach opportunities, among others. This is most clearly encapsulated in comments from a student-participant, "This REU has changed my life for the better. I do not regret all the effort I put into this REU and getting it brought me happiness and for trusting it is life changing. I'm grateful for taking this opportunity".

Participants were asked to rate their level of knowledge of how to conduct research and their level of confidence in conducting research at the beginning and end of the program. Participants' knowledge and confidence at the outset was low, with $10 \%$ rating their knowledge as high to very high and $20 \%$ rating their confidence as high to very high. At the conclusion of the program, $60 \%$ rated both their confidence and knowledge as high to very high, reflecting a statistically significant change (knowledge-pre: $\mathrm{M}=4.4, \mathrm{SD}=1.174$, post: $\mathrm{M}=5.7$, $\mathrm{SD}=.949 ; \mathrm{t}(9)=-3.881, \mathrm{p}=.004$, confidence: pre: $\mathrm{M}=4.3, \mathrm{SD}=1.418$, post: $\mathrm{M}=5.6, \mathrm{SD}=.843 ; \mathrm{t}(9)=-2.899, \mathrm{p}=.018)$.

At the conclusion of the program, participants were asked additional questions to gain insight into their gains in research skills. Participants were asked to rate their knowledge and ability with respect to the scientific concepts related to their research projects. Eighty percent rated their understanding of the guiding theory and concepts related to their projects as high or very high. With respect to identifying limitations of research methods and designs, 90\% rated their ability as high to very high. With respect to using problem solving skills in the research process, $70 \%$ rated their abilities as high or very high.

Mentoring may be credited with participants' gains in developing research skills, based on responses to questions asked at the conclusion of the program. With respect to mentors, $70 \%$ of participants reported they agreed or strongly agreed that they learned a lot from their mentors and $60 \%$ rated the quality of faculty mentoring as high or very high. Graduate Student/Post Doc mentoring quality received a very high rating from $67 \%$ of participants. Participants spent significant amounts of time with their mentors, based on their self-reporting of the number of hours spent per week with faculty, post-doc and graduate student mentors. Sixty percent of participants reported spending a minimum of ten hours a week with mentors, with $40 \%$ reporting spending 20 or more hours per week with mentors.

\subsection{Sustainability Impact}

The sustainability impact of the program was defined by important outputs and outcomes. Specifically, both near-term and long-term effects on participants from various aspects such as education, career, community, and life were considered. Qualitative analysis revealed that motivation was indeed an important 
factor and strongly related to participants' intentions in pursuing environmental sustainability careers. Many students noted their inherent interests in sustainability which were advanced through the program and became a part of envisioned ideal jobs and influenced hopes to teach sustainability. In terms of external motivation, networking and learning professional skills appeared to influence student perspectives on career choice. REU students indicated that the program was effective in expanding their knowledge on environmental concepts and in teaching them how to apply engineering principles to sustainability-related problems. It was reported that there is an early learning curve. However, when offering instructive suggestions for future groups of participants, challenges with low perceived initial skill proficiency were noted by students as opportunities to continue learning and not to be discouraged. Participants demonstrated high levels of intrinsic motivation and this helped them explore and enhance their competence through the research program and related enrichment activities.

Participants were asked questions about their future career plans at three points in time (at the outset and conclusion of the program and six months afterward). They were asked to identify the level of clarity they had about their future career path on a pre-post survey. At the outset of the program, 50\% reported a high or very high level of clarity. At the conclusion, 90\% reported a high or very high level of clarity. A paired samples t-test comparing the pre-post differences showed they were significant (pre: $M=4.3, S D=1.160$, post: $M=$ $5.3, \mathrm{SD}=.823 ; \mathrm{t}(9)=-3.0, \mathrm{p}=.015)$. While $50 \%$ of the participants entered the program with a high level of clarity about their future career path, $80 \%$ agreed or strongly agreed that the program helped them develop a better idea of their future career paths. For many participants, their future career paths involve sustainability. Six months after participating in the program, 63\% agreed or strongly agreed they plan to pursue a career involving environmental sustainability.

In addition to measuring participants' level of clarity about careers involving environmental sustainability, the quantitative data established that participants' knowledge of environmental sustainability was strengthened. Seventy percent of participants indicated that they had a somewhat high to very high level of knowledge about environmental sustainability at the end of the program. While the difference in means was not statistically significant for this question, there was a shift in pre-post responses. On the pre-survey, only 30\% reported that their knowledge of environmental sustainability was high to very high. Findings also revealed that participants place a high level of importance on sustainability and the role of research in addressing environmental problems (80\% agreed or strongly agreed that research is important to addressing current environmental issues). While participants entered the program reporting a high regard for environmental sustainability, the program did impact their broadening perspectives about sustainability and enhance their understanding of it. Eighty percent of participants agreed or strongly agreed that as a result of the REU, they viewed 
sustainability as an applied, multidisciplinary field.

\subsection{Discussion}

Synthesizing the competency and program elements into an integrated model helps demonstrate the overall utility of combining theory and practice. Figure 4 includes the components and the linkages. A practical example of utilizing the competencies problem-solving framework for EW\&F REU learning involves design, analysis, and tradeoffs of sustainable energy systems. Individual research projects were focused on biofuels, wind power, innovative batteries, and electrification of transportation, among others. Working through the illustrated system progressively from left to right, student-participants began by defining the complex problem for diagnosis and formulating research questions while compiling baseline data on extant conditions for their respective projects (requiring systems thinking). Strategic approaches were used to develop a sustainable vision with long-term goals, technology trajectories, and potential impacts of non-renewable and alternative energy modalities (requiring anticipatory and normative competencies); these were informed by weekly seminars, brown bags, group projects, and field trips. Interdisciplinary teams of students, peers, mentors, industry representatives, and community stakeholders worked in collaboration to evaluate needs, potential points and feasibility of intervention scenarios (including non-action option as required by the National Environmental Policy Act procedural process), and sustainability transitions to go from energy problem to envisaged solution. These pragmatic efforts involved basic and applied investigations, unpacking policy puzzles, and disseminating knowledge through public forums such as the Annual Dialog on Sustainability. Overall, interpersonal capabilities which are comprehensively essential were cultivated, tested, and strengthened throughout the entire research and outreach spectrum.

\section{Conclusion}

The need for professionals, leaders, and stakeholders competent in sustainability is clear. Finding ways to effectively address this is an ongoing educational challenge. REU models for participant motivation to develop core competencies and research skills for impacting sustainability are demonstrating success. Based on an innovative and diverse programmatic structure for summer learning and service, the conceptual MCRS framework as an organizing tool was presented through mixed methods of analysis. The analysis of the results of this summer REU indicates that $50 \%$ of the students have an increased desire to attend graduate school, $80 \%$ developed a better idea of their future career path, $63 \%$ plan to pursue a career related to environmental sustainability and $90 \%$ reported a high level of clarity with respect to their future career path. All of the students grew in their understanding of environmental sustainability. The results of the MCRS framework provided a good understanding of the impact of the REU program on the lives of the students. Further research is suggested to further define key 
variables and apply the approach to other STEM contexts.

\section{Acknowledgements}

This research was partially funded by a grant from the National Science Foundation Research Experience for Undergraduates Award Number EEC-1460776 and from the Kansas State University Center for Hazardous Substance Research.

\section{References}

American Association for the Advancement of Science (AAAS) (2010). Core Competencies in Sustainability. In Annual Meeting: Bridging Science and Society, Forum for Sustainability Science Programs (pp. 1-18). San Diego, CA: AAAS Workshop Guide.

Arbuthnott, K. D. (2009). Education for Sustainable Development beyond Attitude Change. International Journal of Sustainability in Higher Education, 10, 152-163. https://doi.org/10.1108/14676370910945954

Astin, A. W. (1993). What Matters in College? Four Critical Years Revisited. San Francisco, CA: Jossey-Bass.

Bledsoe, T., \& Baskin, J. J. (2014). Recognizing Student Fear: The Elephant in the Classroom. College Teaching, 62, 32-41. https://doi.org/10.1080/87567555.2013.831022

Bowen, W. G., \& Rudenstine, N. L. (1992). In Pursuit of the PhD. Princeton, NJ: Princeton University Press.

Cayanus, J., \& Martin, M. (2008). Teacher Self-Disclosure: Amount, Relevance, and Negativity. Communication Quarterly, 56, 325-341. https://doi.org/10.1080/01463370802241492

Charmaz, K. (2006). Constructing Grounded Theory: A Practical Guide through Qualitative Analysis. Thousand Oaks, CA: Sage Publications.

Cloud Institute for Sustainability Education (2009). What Is Education for Sustainability (EfS)? http://cloudinstitute.org/our-approach/

Cox, R. D. (2009). The College Fear Factor: How Students and Professors Misunderstand Each Other. Cambridge, MA: Harvard University Press. https://doi.org/10.4159/9780674053663

Deci, E. L., \& Ryan, R. M. (1985). Intrinsic Motivation and Self-Determination in Human Behavior. New York, NY: Plenum. https://doi.org/10.1007/978-1-4899-2271-7

Ehrenfeld, J.R. (2008). Sustainability by Design. New Haven, CT: Yale University Press.

Erickson, L. E., Griswold, W., Hohn, K., \& Saulters, O. S. (2010). Enriching and Evaluating Sustainability Education. Journal of Sustainability Education, 1, 1-20.

Erickson, L. E., Robinson, J., Brase, G., \& Cutsor, J. (2017). Solar Powered Charging Infrastructure for Electric Vehicles: A Sustainable Development. Boca Raton, FL: CRC Press, Taylor and Francis.

Goldin, E., Erickson, L.E., Natarajan, B., Brase, G., \& Pahwa, A. (2014). Solar Powered Charge Stations for Electric Vehicles. Environmental Progress and Sustainable Energy, 33, 1298-1308.

Gonzalez, C. (2001). Undergraduate Research, Graduate Mentoring, and the University's Mission. Science, 293, 1624-1626. https://doi.org/10.1126/science.1062714

Gregerman, S. R., Lerner, J. S., von Hippel, W., Jonides, J., \& Nagda, B. A. (1998). Undergraduate Student-Faculty Research Partnerships Affect Student Retention. The Review of Higher Education, 22, 55-72. https://doi.org/10.1353/rhe.1998.0016 
Hathaway, R. S., Nagda, B. A., \& Gregerman, S. R. (2002). The Relationship of Undergraduate Research Participation to Graduate and Professional Education Pursuit: An Empirical Study. Journal of College Student Development, 43, 614-631.

Hearn, J. C. (1987). Impacts of Undergraduate Experiences on Aspirations and Plans for Graduate and Professional Education. Research in Higher Education, 27, 119-141. https://doi.org/10.1007/BF00992365

Hegarty, N. (2010). Application of the Academic Motivation Scale to Graduate School Students. The Journal of Human Resource and Adult Learning, 6, 48-55.

Hinkle, D. E., Wiersma, W., \& Jurs, S. G. (2003). Applied Statistics for the Behavioral Sciences. Boston, MA: Houghton Mifflin Company.

Incropera, F. P. (2016). Climate Change: A Wicked Problem. New York, NY: Cambridge University Press. https://doi.org/10.1017/CBO9781316266274

Kamil Anil, N., \& Eti Icli, G. (2013). MBA Students' Satisfaction and Loyalty: State vs. Private Universities in Turkey. Trziste/Market, 25, 17-198.

Khanam, A., Iqbal, S., \& Muhammad Khan, A. (2012). Effect of Educators' Immediacy on Prospective Teachers' Learning. Journal of Research \& Reflections in Education, 6, 137-144.

Kober, N. (2015). Reaching Students: What Research Says about Effective Instruction in Undergraduate Science and Engineering. Washington DC: Board on Science Education, Division of Behavioral and Social Sciences and Education, The National Academies Press.

Köseoğlu, Y. (2013). Academic Motivation of the First-Year University Students and the Self-Determination Theory. Educational Research and Reviews, 8, 418-424.

Leve, J., \& Wegner, E. (1991). Situated Learning: Legitimate Peripheral Participation. Cambridge: Cambridge University Press. https://doi.org/10.1017/CBO9780511815355

McClelland, D. C. (1967). The Achieving Society. New York, NY: Simon and Schuster.

Mertens, D. M., \& McLaughlin, J. A. (2004). Research and Evaluations Methods in Special Education. Thousand Oaks, CA: Sage Publications.

https://doi.org/10.4135/9781412985666

National Research Council (2011). Sustainability and the U.S. EPA. Washington DC: The National Academies Press.

National Science Board (2009). Building a Sustainable Energy Future: U.S. Actions for an Effective Energy Economy Transformation. NSB-09-35.

Pascarella, E. T., \& Terenzini, P. T. (1991). How College Affects Students. San Francisco, CA: Jossey-Bass.

Robinson, J., Brase, G., Griswold, W., Jackson, C., \& Erickson, L. (2014). Business Models for Solar Powered Charging Stations to Develop Infrastructure for Electric Vehicles. Sustainability, 6, 7358-7387. https://doi.org/10.3390/su6107358

Ryan, R., \& Deci, E. L. (2000). Intrinsic and Extrinsic Motivations: Classic Definitions and New Directions. Contemporary Educational Psychology, 25, 54-67.

https://doi.org/10.1006/ceps.1999.1020

Sachs, J. D. (2015). The Age of Sustainable Development. New York, NY: Columbia University Press. https://doi.org/10.7312/sach17314

Seymour, E. (1995a). Revisiting the Problem Iceberg; Science, Mathematics, and Engineering Students Still Chilled Out: Examining the Causes of Student Attrition in Science-Based Fields on a Variety of Campuses. Journal of College Science Teaching, 24, 392-400. 
Seymour, E. (1995b). The Loss of Women from Science, Mathematics, and Engineering Undergraduate Majors: An Explanatory Account. Science Education, 79, 437-473.

https://doi.org/10.1002/sce.3730790406

Teddlie, C., \& Tashakkori, A. (2009). Foundations of Mixed Methods Research: Integrating Qualitative and Quantitative Approaches in the Social and Behavioral Sciences. Thousand Oaks, CA: Sage Publications.

The Guardian (2007). Bali Climate Change Conference 2007. https://www.theguardian.com/environment/2007/dec/12/bali.climatechange1

Tinto, V. (1993). Leaving College: Rethinking the Causes and Cures of Student Attrition (2nd ed.). Chicago: The University of Chicago Press.

Van Soom, C., \& Donche, V. (2014). Profiling First-Year Students in STEM Programs Based on Autonomous Motivation and Academic Self-Concept and Relationship with Academic Achievement. PLoS ONE, 9, e112489. https://doi.org/10.1371/journal.pone.0112489

Wiek, A., Withycombe, L., \& Redman, C. L. (2011). Key Competencies in Sustainability: A Reference Framework for Academic Program Development. Sustainability Science, 6, 203-218. https://doi.org/10.1007/s11625-011-0132-6

Zydney, A. L., Bennett, J. S., Shahid, A., \& Bauer, K. W. (2002). Impact of Undergraduate Research Experience in Engineering. Journal of Engineering Education, 91, 151-157. https://doi.org/10.1002/j.2168-9830.2002.tb00687.x 